\title{
O ESTÁGIO SUPERVISIONADO: FIOS, DESAFIOS, MOVIMENTOS E POSSIBILIDADES DE FORMAÇÃO
}

\author{
LAS PRÁCTICAS SUPERVISADAS: HILOS, RETOS, MOVIMIENTOS Y \\ POSIBILIDADES DE FORMACIÓN
}

\author{
THE SUPERVISED INTERNSHIP: LINES, CHALLENGES, \\ MOVEMENTS AND POSSIBILITIES OF FORMATION
}

\author{
Luís Tavora Furtado RIBEIRO ${ }^{1}$ \\ Osmar Hélio Alves ARAÚJO²
}

RESUMO: Discute-se aqui o estágio supervisionado como um processo que deve possibilitar aos estagiários fazer uso constante do diálogo, da indagação e da reflexão sobre as experiências, as habilidades, as atitudes e os conhecimentos construídos e em construção, buscando sempre dar significado às aprendizagens apreendidas a partir deste processo. Com base em pesquisas e ensaios relevantes sobre o tema, busca-se aqui sublinhar a experiência do estágio como um processo contínuo e dinâmico de aprendizagens acerca da profissão docente, assim como suas relações com os variados territórios e tempos e, ainda, os modos de ser, de fazer e de estar na profissão. Concluise sublinhando a importância de se vivenciar uma experiência do estágio ancorando-se em uma perspectiva crítica-reflexiva, assim como a relevância da participação, do interesse e do estagiário manter uma postura ativa nas atividades realizadas no estágio.

PALAVRAS-CHAVE: Estágio supervisionado. Formação docente. Contexto escolar.

RESUMEN: Se discute aquílas prácticas supervisadas como un proceso que debe posibilitar a los becarios hacer uso constante del dialogo, de la indagación y de la reflexión acerca de las experiencias, las habilidades, las actitudes y los conocimientos construidos y en construcción, buscando siempre darles significado a los aprendizajes incautados desde este proceso. Basado en investigaciones y ensayos relevantes al tema, buscase aquí subrayar la experiencia de los becarios como proceso continuo y dinámico de aprendizajes con respeto a la profesión docente, así como sus relaciones con los variados territorios y tiempo y, todavía, las maneras de ser, de hacer y de estar en la profesión. Se concluye subrayando la importancia de vivenciar una experiencia de prácticas anclándose en una perspectiva critico-reflexiva, bien como la relevancia de la participación, del interés y del becario en mantener una postura activa en las actividades hechas en las prácticas.

PALABRAS-CLAVE: Prácticas supervisadas. Formación docente. Contexto escolar.

${ }^{1}$ Universidade Federal do Ceará (UFC), CE - Brasil. Docente na graduação e pós-graduação (mestrado e doutorado em Educação) nas linhas: Educação, Currículo e Ensino e História e Memória da Educação. Email: luistavora@uol.com.br

${ }^{2}$ Universidade Federal da Paraíba (UFPB), PB - Brasil. Doutorando em Educação. E-mail: osmarhelio@hotmail.com 
ABSTRACT: It is discussed here the supervised internship as a process that should allow interns to make constant use of dialogue, of inquiring and of reflection over the constructed and under construction experiences, abilities, attitudes and knowledge, aiming always to provide meaning to the apprehend apprenticeship from this process. Based on relevant researches and essays regarding the theme, it is aimed here to highlight the experience of the internship as a continuum and dynamic process of apprenticeship regarding the teaching profession, as well as its relations with the several territories and times and, even so, the ways of being, doing and laying in the profession. It is concluded highlighting the value of living the experience of the internship anchoring in a critic-reflexive perspective, as well as the significance of the participation, the interest and the intern to maintain an active posture in the activities performed in the internship.

KEYWORDS: Supervised internship. Teaching formation. School context.

\section{Considerações iniciais}

O estágio supervisionado deve ser um processo contínuo de formação, crescimento pessoal e profissional para os licenciandos que devem, nesse sentido, serem sujeitos ativos para que a aprendizagem acerca da profissão docente efetivamente se materialize. Entende-se, a princípio, que a experiência do estágio supervisionado levará os licenciandos a compreenderem a instituição escolar à medida que forem se inserindo em situações concretas do fazer pedagógico. Dessa forma, o estágio deve ser uma jornada contínua de formação e aprendizagens acerca do exercício docente, pois vislumbra-se a realização do estágio supervisionado para além de uma atividade obrigatória, haja vista que esta experiência oportunizará aos licenciandos entrecruzarem conhecimentos teóricos com situações práticas do fazer docente. Logo, esse processo exige do estagiário compromisso e seriedade.

No rastro do exposto, este debate sustenta a tese que o estágio deve ser um instrumento de formação, a partir do qual o estagiário deve estabelecer um contraponto entre teoria e prática, assim como vivenciar experiências significativas e construir saberes e práticas tendo como suporte um trabalho de reflexão sobre a prática empreendida, de modo a buscar alternativas para uma nova ação educativa. Diversos autores tratam do tema em questão com abordagens e olhares diferentes. Visando atingir o objetivo proposto, tomamos como base alguns desses trabalhos, mais relevantes para o escopo desta discussão. Dentre eles, podemos citar: Shon (1992), Brasil (1996), Freire (1996), Libâneo (2002), Monteiro (2002), Lima (2004, 2008), Adrião et al., (2009 
Pimenta e Lima (2009), Luckesi (2008), Brandão (2008), Azevedo e Andrade (2011), Milanesi (2012), Freitas (2014), Franco (2015), Araújo e Ribeiro (2016) Mascarenhas e Franco (2017).

Em um tom sumário, este ensaio se encontra organizado em duas partes, além desta introdução e de uma conclusão. Primeiramente, sublinha-se o estágio supervisionado como instrumento de formação dos alunos de licenciatura. Em seguida, discorre-se sobre as contribuições do estágio para a aprendizagem da profissão docente.

Do estágio durante a formação dos alunos de licenciatura espera-se, portanto, que seja propiciada a vivência da dimensão da totalidade da prática docente, o que o caracterizará como uma jornada de mobilização de saberes e construção de conhecimentos a partir dos elementos constituintes do movimento da prática educativa a ser realizada.

\section{Estágio supervisionado como instrumento de formação}

Compreende-se aqui que o estágio supervisionado deve possibilitar aos alunos de licenciatura dialogar com a escola e com os sujeitos que a habitam. Em concordância com Lima (2004), o estagiário, agindo sobre o meio e recebendo a influência deste, pode elaborar o seu conhecimento de modo indissociável da realidade social através da reflexão, da troca de experiências e interferindo, de algum modo, nesta mesma realidade. Nesse sentido, estagiar é se inserir no contexto escolar em uma perspectiva crítica-reflexiva (práxis) ${ }^{3}$.

Tal compreensão associada à obrigatoriedade do estágio nos cursos de formação docente faz emergir a necessidade de discussões sobre a validade dessa experiência para a formação dos professores. É fundamental trazer para o debate as possibilidades e limites do estágio supervisionado como um instrumento formativo, posto que a formação do professor no espaço universitário se insere em um contexto social de desafios institucionais, atrelados às exigências relacionadas com prazos e produção científica.

${ }^{3}$ Neste texto, "A práxis é compreendida a partir da filosofia marxista como uma atitude (teórica-prática) humana de transformação da natureza e da sociedade. Não basta conhecer e interpretar o mundo (teórico),é preciso transformá-lo (práxis). Entender a práxis como prática é uma percepção reduzida, pois nem toda prática transforma a realidade. A práxis é uma atividade transformadora, consciente e intencionalmente realizada" (MASCARENHAS E FRANCO, 2017, p. 47). 
Um tópico que, a priori, se mostra necessário para o debate é a compreensão que a possibilidade do estágio supervisionado ser considerado como práxis, como jornada formativa, passa igualmente pela figura do professor orientador, sua história de vida, seus valores, visão de mundo e de ciência. Essa ideia encontra reforço nas contribuições de Lima (2004), quando a autora afirma que o orientador do estágio supervisionado é um intelectual integrante de uma classe privilegiada da sociedade, o qual teve acesso a todos os graus de instrução, e que, portanto, está teoricamente formado para exercer $\mathrm{o}$ ato educativo de maneira consciente e com fundamentação cientifica. Agrega-se aqui que o orientador do estágio atua no campo da formação e da prática pré-profissional dos futuros professores, tendo um papel determinante na formação dos docentes (AZEVEDO; ANDRADE, 2011).

Vale destacar, portanto, que o supervisor do estágio deve ser um facilitador e orientador de todo o processo para assim, certamente, enriquecer esta experiência que trará contribuições significativas para a formação dos futuros professores. Entretanto, Monteiro (2002) chama a atenção ao afirmar que a orientação dos estagiários acaba sendo uma extensão da jornada de trabalho dos professores orientadores que, na maioria das vezes, sem a necessária remuneração, acabam por permitirem que os alunos os substituam em sala de aula, de modo precário e sem as devidas instruções.

Ainda de acordo com Monteiro (2002), os professores orientadores de estágio, cujas práticas pedagógicas sofrem as marcas da sociedade e das exigências a que estão submetidos, vivem uma corrida em busca de melhores condições econômicas e, não raramente, acabam dispondo de tempo insuficiente para a leitura, a preparação das aulas e orientação dos estagiários, que ocorrem paralelamente à pesquisa e demais tarefas acadêmicas. Lima (2008) endossa este ponto de vista, sinalizando que os professores assumem o papel de orientador, dos estagiários e das escolas recebedoras, dentro de suas limitações e possibilidades de tempo, espaço e condições objetivas de trabalho da universidade. Isso nos leva a compreender que o orientador do estágio supervisionado, mesmo em um emaranhado de limitações e possibilidades de trabalho, deve atuar a partir do seu lugar específico, da sua experiência e formação, sem se apresentar como portador de soluções para as questões que irão emergir a partir da incursão dos licenciandos na instituição escolar.

Deste modo, convém advertir que a formação inicial dos professores não deve ser um processo alheio ao contexto escolar, ao processo educacional vivenciado dentro das escolas brasileiras, pois a integração dos mesmos com seu futuro campo de atuação 
é o que diferencia uma formação producente de um processo meramente instrumentalizador. Defendendo o mesmo raciocínio, Milanesi (2012) enaltece que é no exercício da profissão, no "chão" da escola, que o estagiário se constitui professor, posto que a escola é um contexto rico de oportunidades de aprendizado diversas e constituída por alunos que vivenciam ações planejadas ou não. Adicionalmente, é necessário salientar que a integração dos licenciandos com a escola não deve se realizar apenas nos momentos ditos como obrigatórios, como o estágio supervisionado, pois somente essa experiência não é suficiente para a produção de saberes a partir do contexto escolar. A integração dos mesmos com a escola, portanto, deve ser uma questão que perpassa todas as disciplinas, e o estágio deve ser uma vivência que permita aos licenciandos relacionarem as ações vividas com a sua formação.

Como já exposto, não se trata apenas de aproximar ou oferecer aos licenciandos possibilidades de inserção no contexto escolar, mas, sobretudo, trata-se de aproximá-los da perspectiva reflexiva proposta por $\operatorname{Shon}(1992)^{4}$, assim como se trata de tornar o estágio supervisionado:

[...] num momento marcante da vida profissional, onde as primeiras experiências de ensino são realizadas com apoio de professores e colegas, que auxiliam a superação de barreiras e medos suscitados por uma atividade que tem no relacionamento humano, com todos os seus imponderáveis, o principal eixo de atuação (MONTEIRO, 2002, p. 141).

No intuito de fortalecer a posição da autora, realça-se aqui que a inserção dos licenciandos no contexto escolar, seja por meio do estágio supervisionado ou outras atividades, se transforma em um compromisso político que visa transformar não apenas o professor em formação, mais também as bases estruturais da sua formação. Por isso, nenhum processo que objetiva a formação dos professores pode ficar alheio à realidade das escolas brasileiras. $\mathrm{O}$ processo de formação inicial docente perde sua efetividade se não houver no seu interior efetiva integração com o processo pedagógico das escolas por meio da práxis. Luckesi (2008) entra no debate assinalando que:

Formar o educador, a meu ver, seria criar condições para que o sujeito se prepare filosófica, científica, técnica e afetivamente para o tipo de ação que vai exercer. Para tanto, serão necessárias não só aprendizagens cognitivas sobre os diversos campos de conhecimento que o auxiliem no desempenho do seu papel, mas especificamente o

${ }^{4}$ Shon (1992) advoga a ideia do professor como sujeito reflexivo, pesquisador, intelectual e crítico. 
desenvolvimento de uma atitude, dialeticamente crítica, sobre o mundo e sua prática educacional (LUCKESI, 2008, p. 28-29)

É nessa perspectiva que não pode faltar aos estagiários o desejo de reconstrução, humildade pedagógica, capacidade de fazer o melhor, pois os mesmos devem empreender esforços visando construir suas práticas pedagógicas em favor da construção de uma educação de qualidade e que responda aos anseios da sociedade e em inserira o homem, profissional e emocionalmente, no meio social. Pois,"A educação é um processo de humanização, Ou seja, é processo pela qual se possibilita que os seres humanos se insiram na sociedade humana, historicamente construída e em construção" (PIMENTA E ANASTASIOU, 2003, p. 97). Esta questão se mostra como um desafio ao estágio supervisionado que deve ter como propósito promover, robustecer e proporcionar o desenvolvimento profissional do professor, tomando o contexto escolar como arena de formação. A meta do estágio deve ser formar o professor com renovada militância pedagógica, à luz da pedagogia e da didática já que estas, considerando que a atividade docente está centrada nos processos de ensino e aprendizagem,auxiliam na estruturação de novas possibilidades de ensinar e aprender.

Nesta perspectiva, compreende-se que os professores em formação devem participar, de modo criativo e inovado, da construção e reconstrução destes processos, pois, de acordo com Pimenta e Lima (2009), o conhecimento prático de como assegurar a aprendizagem é consequência da atividade de ensinar. Deste modo, a didática deve estar a serviço dos professores em formação, possibilitando que os mesmos participem conjuntamente da construção de práticas pedagógicas que contribuam para o desenvolvimento da sociedade. Conforme nos lembram Pimenta e Lima (2009, p. 186) a didática constitui-se "[...] em instrumental importante para a ampliação da unidade entre a teoria e a prática do trabalho dos professores [...]".

O período do estágio supervisionado, antes de ser um ponto de chegada, é um ponto de partida para a produção de novos saberes a partir da arena escolar. Conforme nos explicita Monteiro (2002, p. 142) "é preciso que a Prática de Ensino se desenvolva em novos moldes. Não vamos mais propor a reprodução de modelos de aulas e, sim, a vivência de experiências significativas". É possível acoplar as contribuições de Libâneo (2002), ao advertir que: 


\begin{abstract}
A formação teórica e prática implica algo como um vai-e-vem entre o estudar e o fazer, mas cujo resultado é o saber fazer com consciência. Não se pode tolerar mais a formação teórica e prática precárias, ao contrário, é preciso cuidar do aprofundamento teórico nas disciplinas propriamente pedagógicas e admitir que o trabalho nas escolas e nas salas de aula implicam "um saber-fazer" que necessita ser assunto do currículo (LIBÂNEO, 2002, p. 35).
\end{abstract}

Em acordo com o pensamento dos autores, importa salientar que se faz necessário ainda que os conhecimentos do campo da pedagogia penetrem nas estruturas teóricas prévias dos estagiários a fim de fortalecera a sua autonomia pedagógica, pois não se trata de ser um mero repetidor de práticas de outros. Nesta perspectiva, os estagiários precisarão se empenhar para construírem suas próprias práticas, sendo imprescindível o domínio dos conhecimentos dos campos da pedagogia e da didática. Conforme enfatizam Araújo e Ribeiro (2016), os conhecimentos desses campos precisarão sempre ser retomados na formação docente para serem aprofundados e problematizados.

Na próxima seção, enfocaremos na discussão as contribuições que o estágio supervisionado oferece à aprendizagem da profissão docente.

\title{
As contribuições do estágio supervisionado na aprendizagem da profissão docente
}

Começamos essa seção trazendo para o debate as contribuições de Freire (1996). Segundo o autor, é a capacidade de olhar com curiosidade o mundo em sua volta, de se “espantar" em face dele, assim como de atuar sobre ele e perceber as coisas a partir dessa atuação e do olhar sobre essa atuação que o homem se tornou "bicho-gente", isto é, a aprendizagem sobre as coisas vai sendo construída ao longo da elaboração das mesmas, ao tempo em que, ao fazê-las, o ser humano muda o mundo e a si mesmo. Nesta perspectiva, o estágio supervisionado, enquanto disciplina obrigatória nos cursos de licenciaturas, deve ser apresentado como uma possibilidade de levar os alunos a conhecerem, entenderem e vivenciarem a realidade da educação básica ${ }^{5}$. Como explica

${ }^{5}$ A Educação Básica, um dos níveis de abrangência da educação escolar no Brasil, é composta pela Educação Infantil (primeira etapa), Ensino Fundamental (etapa gratuita e obrigatória) e Ensino Médio (etapa final, gratuita, mas com oferta progressiva) (LDB - Art. 21 a 28). Cabe-lhe desenvolver formação humana que assegure aos educandos conhecimentos que propiciem o exercício da cidadania e forneçalhes meios para progredir no trabalho e em estudos posteriores (Art. 22). Os fins de cada uma dessas 
Brandão (2008, p. 59), falta nos cursos de formação docente um "pé na realidade", "ou seja, falta a contextualização ou enraizamento na realidade do nosso ensino, das nossas escolas e de sua clientela e as condições da prática profissional do nosso professor".

O que podemos inferir das ideias de Brandão é que a experiência do estágio deve abrir espaço para que o professor em formação, em uma perspectiva crítica, reflita sobre a prática de exercer a docência. $O$ estágio é o momento essencial para a observação e a compreensão das peculiaridades da educação básica, assim como do cotidiano do trabalho docente. Tal compreensão deve se pautar na observação crítica dos movimentos pedagógicos que ocorrem no ambiente escolar a fim de perceber os fenômenos imbricados a esse contexto. Portanto, é importante assimilar que:

[...] é necessário que o estagiário aprenda a exercitar um olhar pedagógico e atento para entender o que há de estranho nas coisas comuns. Quando estamos atentos para o movimento da sala e seu cotidiano, podemos verificar o que não se aprende, o que se ensina, a interação entre os alunos, as possibilidade e contradições entre alunos e professores (LIMA, 2008, p. 203).

Desse modo, faz-se necessário fugir de uma experiência de estágio lacunosa, burocrática e reguladora para uma experiência docente mais participativa, autônoma, realista e formadora, isto é, os licenciandos devem abraçar com determinação seu processo formativo. Nesta perspectiva, os mesmos devem estar atentos às demandas que emergem do contexto escolar e que, portanto, corroboram para a atualização e aprofundamento das bases teóricas capazes de sustentarem as práticas pedagógicas.

O estágio supervisionado, dessa forma, deve ser um momento de reflexão em uma perspectiva crítica e construtiva sobre a ação docente, buscando compreender a dimensão social da prática pedagógica. Segundo Pimenta e Lima (2009):

[...] a profissão de educador é uma prática social. Como tantas outras, é uma forma de se intervir na realidade social, no caso por meio da educação que ocorre não só, mas essencialmente, nas instituições de ensino. Isso porque a atividade docente é ao mesmo tempo prática e ação (PIMENTA e LIMA, 2009, p. 41).

Recorre-se aqui a Franco (2015), com o intuito de melhor explicitar a ação docente como prática social. A referida autora expõe que:

etapas, alinhados a esse macro objetivo, estão detalhados em seções e artigos específicos da mesma Lei (Art. 29 a 36). 
[...] só a ação docente, realizada como prática social, pode produzir saberes, saberes disciplinares, saberes referentes a conteúdos e sua abrangência social, ou mesmo saberes didáticos, referentes às diferentes formas de gestão de conteúdos, de dinâmicas da aprendizagem, de valores e projetos de ensino (FRANCO, 2015, p. 607).

A partir das contribuições das autoras fica evidente que cada estagiário se encontra simultaneamente chamado a atualizar e aprofundar os parâmetros teóricos que o possibilitará construir "novas" práticas pedagógicas capazes de transformar o mundo e envolver os discentes em experiências significativas de aprendizagem. Não se trata, portanto, de impor aos licenciandos um modelo pedagógico a ser seguido. Tampouco se trata de discurso ou orientações sancionadoras, ou de assentá-los passivamente no contexto escolar, a partir da experiência do estágio supervisionado, a fim de assistir as “boas” práticas pedagógicas sem espaço para a reflexão e a reconstrução. Trata-se de olhar o estágio como instrumento para compreender a prática docente em uma perspectiva construtiva em detrimento da reprodução mecânica de modelos prontos. Por isso, entende-se aqui que o estágio, enquanto elemento formativo, abarca também a dimensão social. Afinal, não é apenas o estagiário que é formado por meio da sua experiência, mas também todos os sujeitos envolvidos em suas relações no contexto escolar. Assim, a dimensão social deve ser típica da essência da experiência do estágio supervisionado, de maneira que exista um conteúdo social capaz de fazer emergir a constituição da identidade docente, assim como perpassado por sensibilidade fundamental para a educação das pessoas e da sociedade.

Face ao exposto, o passo seguinte é importante. Não é possível entender simplesmente o estágio como consequência da obrigatoriedade, algo que parece ser óbvio. Também não é possível dizer que a formação docente nos cursos de licenciatura não está relacionada com a escola e que o estágio é simplesmente a observação de práticas docentes. Ao contrário, os caminhos do estágio supervisionado e as etapas a serem desbravadas devem levar os licenciandos a se sentirem engajados no aprofundamento do processo educacional vivenciado no contexto escolar. Por isso, fazse necessário um estagiário que não se satisfaça em si mesmo, mas vá ao encontro do processo educacional, das pessoas, da sociedade e da escola, para ali vivenciar uma autêntica prática pedagógica que, além de formadora, seja também transformadora do meio social. Milanesi (2012) nos chama atenção dizendo que o estágio, se bem 
realizado e compreendido, produzirá marcas significativas para o ingresso na profissão e contribuirá para a transformação da realidade escolar.

Esta perspectiva desafia professores e estagiários a darem um passo para além da mera compreensão do estágio como a simples inserção dos licenciandos no contexto escolar, já que a preocupação fundamental do estágio deve ser com a formação docente como um todo. Essa noção de estágio como instrumento de formação é que deve nortear todo o processo de formação dos professores. Isto é, o estágio é entendido como o momento de construção de saberes e experiências, cuja função é a formação dos professores em uma perspectiva reflexiva, ou seja, como práxis, ação - reflexão - ação. Nas palavras de Franco (2015, p. 607): “quando um professor é formado de modo não reflexivo, não dialógico, desconhecendo os mecanismos e movimentos da práxis, ele não saberá potencializar as circunstâncias que estão postas à prática. Ele desistirá e replicará fazeres".

Destarte, o estágio supervisionado deve ter como objetivo levar os licenciandos a apreender intensamente a profissão docente, assim como a fazer um contraponto entre a teoria e a prática, pois, na maioria das vezes, os estagiários não conseguem estabelecer articulações entre as teorias discutidas em salas de aulas e as práticas pedagógicas empreendidas no período do estágio. Tal fato se explica, talvez, pelo distanciamento que há entre os conteúdos trabalhados nas universidades e a realidade existente no contexto escolar. Desse modo, não são os licenciandos que devem existir em função da escola, mas, ao contrário, é a escola enquanto: [...] "lócus" de construção de saberes e de conhecimentos" (TARDIF, 2002, p. 196), que existe em função também da formação dos professores, seja ela inicial ou contínua. Os licenciandos devem ser inseridos em situações concretas das escolas brasileiras, já que não é possível formar professores pautando-se somente e exclusivamente no "ABSTRATO". Ao se considerar as inúmeras limitações que permeiam o processo de formação docente, é evidente a necessidade de uma formação que possibilite aos licenciandos compreenderem e inserirem-se no cotidiano escolar com olhar crítico e investigativo, conforme estudos realizados por Lima (2008), Milanesi (2012), Pimenta e Lima (2009), entre outros.

Importa ainda ressaltar a necessidade de se incentivar os estagiários a desenvolverem projetos que visem intervir no contexto escolar com um novo olhar, uma nova maneira de exercer e entender a docência a partir de uma reflexão crítica e atualizada. Os resultados advindos disso permitiriam aos estagiários perceberem o valor de seu trabalho e esforço em prol da construção de uma educação, de fato, 
transformadora, emancipatória e cidadã. Nesse sentido, o estágio não deve ter um fim em si mesmo. Trata-se, como já sublinhado, de fazê-lo acontecer sem se resumir à aplicação de aulas modelos de outros professores ou ao cumprimento de normas e orientações previamente estabelecidas, assim como se trata de envolver os estagiários no compromisso com a construção de uma nova sociedade, mais humana e equânime. Afinal, a formação dos professores deve realizar-se em novas relações: em conexão com as mudanças vivenciadas pela sociedade, integrada aos avanços tecnológicos e as novas gerações, entre outros ${ }^{6}$.

Em linhas finais, não podemos deixar de destacar o caráter político do estágio e da formação docente para denunciar os interesses não confessos em belos e elaborados discursos dos reformadores empresariais da educação ${ }^{7}$ que estão a introduzir a padronização/homogeneização de conteúdos e currículos escolares como parâmetro de qualidade da educação brasileira (ADRIÃO et al., 2009, p.807 ).Os quais, segundo Monteiro (2002), acusam os professores de malformados, assim como os responsabilizam pelos resultados dos alunos a partir, meramente, dos parâmetros das avaliações externas. Por isso, o estágio supervisionado deve levar os licenciandos a desenvolverem práticas significativas e intervenientes no meio social, ou seja, que o estágio se caracterize por novas relações estabelecidas entre todos, estagiários, escola e sociedade.

\section{Considerações finas}

Ao se concluir esta discussão não podemos deixar de frisar que a escola não se constitui meramente por simples aglomeração de indivíduos, por uma única classe de sujeitos ou por uma fração destes, mas por relações estabelecidas entre os indivíduos que a compõe e pautadas em princípios que visam concretizar práticas históricas transformadoras. A escola é um contexto plural e, como a educação não se faz por imposição, é imperativo que se cultive e fortaleça no seu contexto a cultura do diálogo,

${ }^{6}$ Essa questão pode ser vista e aprofundada na reflexão de Araújo et al (2016).

7 Segundo Freitas (2014, p. 1109) "Corporate reformers- assim são chamados os reformadores empresariais da educação nos Estados Unidos, em termo criado pela pesquisadora americana Diane Ravitch (2011). Ele reflete uma coalizão entre políticos, mídia, empresários, empresas educacionais, institutos e fundações privadas e pesquisadores alinhados com a ideia de que o mercado e o modo de organizar a iniciativa privada é uma proposta mais adequada para "consertar" a educação americana, do que as propostas feitas pelos educadores profissionais". 
a interação contínua e, antes de tudo, a formação de sujeitos enquanto autores das suas próprias histórias. Nesta perspectiva, conclui-se que o estágio supervisionado é um processo que deve proporcionar aos licenciandos, coletivamente com outros sujeitos, experiências significativas, formadoras e, portanto, transformadoras a partir das múltiplas relações estabelecidas.

Aqui se tentou disseminar uma perspectiva de estágio supervisionado enquanto instrumento de formação. A experiência do estágio, nesse sentido, não deve se resumir à simples observação, regência de sala ou construção de um relatório técnico e desprovido de uma boa base teórica sobre a ação docente e suas implicações na sociedade. Não deve, também, ser entendido como orientações regularizadoras ou como fórmulas sancionadoras, ou diminuído à realização de práticas docentes desarticuladas de um processo dialético transformador. Não negamos aqui as dificuldades existentes em implementar todas essas ideias; contudo, o que se deve buscar é a prática da ação reflexão - ação em vista do estabelecimento de uma formação docente intencionalmente engajada no "fazer", (re)construir a história.

É verdade que o estágio supervisionado se caracteriza por uma preocupação com a formação docente bastante pronunciada, e isso vem de longa data, entretanto, não se trata de levar os estagiários à neutralidade e ao silêncio face à realidade social e escolar em suas diferentes nuances, pois nenhum fazer docente pode ser desprovido de uma opção filosófica - política. Por isso, o período do estágio supervisionado não se esgota na observação de aulas prontas e acabadas ou na apreensão de formulações e aplicação de aulas genéricas. O propósito do estágio deve ser o de alcançar propostas que vise o fomento de atitudes críticas e construtivas frente a uma escola marcada pelo ativismo nem sempre pedagógico, pela busca contínua por resultados em detrimento da reflexão crítica sobre a prática docente.

Afinal, o estágio supervisionado não visa preparar o professor em formação apenas para a educação escolar formal, mas também para atuar diante de um mundo cuja tessitura carrega as marcas da exclusão, da marginalização e de ideologias dominantes, transformando-o em outro, onde a educação se concretize em uma perspectiva humanística e progressista. Este parece ser o ponto central que deve nortear todo o processo de formação docente, o qual o estágio supervisionado pode aprofundar, no sentido de levar os estagiários a perceberem a função social da escola e, mais que isso, a dimensão social do próprio estágio supervisionado. 


\section{REFERÊNCIAS}

ADRIÃO, T.; GARCIA, T.; BORGHI, R.; ARELARO, L. Uma modalidade peculiar de privatização da educação pública: a aquisição de sistemas de ensino- por municípios paulistas. Educação e Sociedade, v. 30, n. 108, p. 799-818, 2009. Disponível em: $<$ http://www.scielo.br/scielo.php?script=sci_arttext\&pid=S0101-73302009000300009 $>$. Acesso em: 12 maio 2017.

ARAÚJO, Osmar Hélio Alves.; RIBEIRO, Luís Távora Furtado. A didática e a pedagogia como suporte teórico para uma coordenação pedagógica qualificada. Revista online de Política e Gestão Educacional, Araraquara, v.20, n.2, p. 501-513, 2016. Disponível em: < http://dx.doi.org/10.22633/rpge.v20.n3.9533>. ISSN: 1519-9029. Acesso em: 29 abr. 2017.

ARAÚJO, Osmar Hélio Alves.; RIBEIRO, Luís Távora Furtado.; PINHEIRO, Maria Nerice dos Santos. Tecnologias móveis nos processos de ensino e de aprendizagem: mobilidade docente? Revista Ibero-Americana de Estudos em Educação. v. 11, n. 1, janeiro/março de 2016. Disponível em: < http://dx.doi.org/10.21723/riaee.2016.v11.n1.p95>. ISSN: 1982-5587. Acesso em: 29 abr. 2017.

AZEVEDO, Maria A. R. de.; Andrade,Maria de F. R. de. O trabalho de orientação dos estágios frente aos diferentes cenários educacionais. Currículo sem Fronteiras, v.11, n.2, pp.147-161, Jul/Dez 2011. Disponível em: <

http://www.curriculosemfronteiras.org/vol11iss2articles/azevedo-andrade.pdf > . Acesso em: 12 maio 2017.

BRANDÂO, Zaia. Abordagens alternativas para o ensino de didática. In: CANDAU, Vera Maria (org.) A didática em questão. 28. Ed. Petrópolis, RJ: Vozes, 2008, p. 5565 .

BRASIL. Conselho Federal de Educação. Conselho Nacional de Educação. Lei no 9.394, de 20 de dezembro de 1996. Disponível em: < http://www.mec.gov.br/legis/pdf/LDB.pdf >. Acesso em: 12 maio 2017.

FRANCO, Maria Amélia Santoro. Práticas pedagógicas de ensinar-aprender: por entre resistências e resignações. Educ. Pesqui., São Paulo, v. 41, n. 3, p. 601-614, jul./set. 2015. Disponível em: <http://www.scielo.br/pdf/ep/v41n3/1517-9702-ep-41-3-0601.pdf $>$. Acesso em: 03 maio 2017.

FREIRE, P. Pedagogia da autonomia: saberes necessários à prática educativa. 13. ed. São Paulo, Paz e Terra, 1996.

FREITAS, Luiz Carlos de. Os reformadores empresariais da educação e a disputa pelo controle do processo pedagógico na escola. Educ. Soc., Campinas, v. 35, nº. 129, p. 1085-1114, out.-dez., 2014. Disponível: Acesso em:<

http://www.scielo.br/pdf/es/v35n129/0101-7330-es-35-129-01085.pdf >. 22 nov. 2016. 
LUCKESI, Cipriano Carlos. O papel da didática na formação do educador. In: CANDAU, Vera Maria (org.) A didática em questão. 28. Ed. Petrópolis, RJ: Vozes, 2008, p. 25-34.

LIMA, Maria Socorro Lucena.A hora da prática: reflexões sobre o estágio supervisionado e ação docente. 4. ed., rev. e ampl. Fortaleza: Edições Demócrito Rocha, 2004. (Coleção magister).

LIMA, Maria Socorro Lucena. Reflexões sobre o estágio supervisionado na formação de professores. Revista Diálogo Educ., Curitiba-PR, v. 8, n. 23, jan./abr/2008, p. 195 205. Disponível em:< http://nead.uesc.br/arquivos/Biologia/mod5bloco4/textoreflexoes_sobre_estagio-e-pratica-de-ensino.pdf >. Acesso em: 28 abr. 2017.

MASCARENHAS, Aline Daiane Nunes.; FRANCO, Maria Amélia Santoro. DE PEDAGOGOS A PROFESSORES: balanço de uma década das diretrizes curriculares dos cursos de pedagogia no Brasil. Revista Internacional de Formação de Professores (RIFP), Itapetininga, v. 2, n.1, p. 41-55, 2017. Disponível em: $<$ http://www.scielo.br/pdf/ep/v41n3/1517-9702-ep-41-3-0601.pdf >. Acesso em: 28 abr. 2017.

MILANESI, Irton. Estágio supervisionado: concepções e práticas em ambientes escolares. Educar em Revista, Curitiba, Brasil, n. 46, p. 209-227, out./dez. 2012. Editora UFPR. Disponível em: <http://www.scielo.br/scielo.php?script=sci_arttext\&pid=S010440602012000400015>. Acesso em: 12 maio 2017.

MONTEIRO, Ana Maria. A prática de ensino e a produção de saberes na escola. In: CANDAU, Vera Maria (org.). Didática, currículo e saberes escolares. 2. ed. Rio de Janeiro: DP\&A, 2002. p. 129-148.

PIMENTA, Selma Garrido; LIMA, Maria Socorro Lucena. Estágio e docência. São Paulo: Cortez, 2009.

PIMENTA, Selma Garrido; ANASTASIOU, Léa das Graças Camargos. Docência no ensino superior. São Paulo: Cortez, 2002. (Coleção Docência em formação).

SCHÖN, Donald A. La formación de profesionales reflexivos. Hacia um nuevo diseño de la enseñanza y aprendizaje emlãsprofisiones. Barcelona: Paidós, 1992.

TARDIF, Maurice. Os professores enquanto sujeitos do conhecimento: subjetividade, prática, e saberes no magistério. In: CANDAU, Vera Maria (org.). Didática, currículo e saberes escolares. 2. ed. Rio de Janeiro: DP\&A, 2002. p. 112-128. 


\section{Como referenciar este artigo}

RIBEIRO, Luís Távora Furtado; ARAÚJO, Osmar Hélio Alves. O ESTÁGIO SUPERVISIONADO: Fios, desafios, movimentos e possibilidades de formação. Revista Ibero-Americana de Estudos em Educação, Araraquara, v. 12, n. 3, p. 17211735 jul-set/2017.

Disponível

em:

<https://dx.doi.org/10.21723/riaee.v12.n.3.2017.10280>. E-ISSN: 1982-5587.

Submetido em: 10/04/2017

Aprovação final em: 16/08/2017 